\title{
Pengaruh Citra Merek, Harga, Promosi dan Electronic Word of Mouth Terhadap Keputusan Pembelian Produk Bedak Padat Wardah Pada PT Pargon Tecnology and Inovation (Studi Kasus Mahasiswa Fakultas Ekonomi STIE Graha Karya Muara Bulian)
}

\author{
Irfan Widyanto', Albetris ${ }^{2}$ \\ ${ }^{1}$ STIE Graha Karya Muara bulian, Muara Bulian, Jambi \\ ${ }^{2}$ Universitas Batanghari, Muara Bulian, Jambi \\ Correspondensce email: irfanwidyanto123@gmail.com, albetris90@gmail.com
}

\begin{abstract}
The first study aims to analyze the Effect of Brand Image, Price, Promotion and Electronic Word of Mouth on Wardah Solid Powder Product Purchase Decisions at the Faculty of Economics STIE Graha Karya Muara Bulian Jambi simultaneously and the second is to determine the effect of Brand Image, Price, Promotion and Electronic Word of Mouth on Wardah Solid Powder Product Purchase Decisions at the Faculty of Economics STIE Graha Karya Muara Bulian Jambi Partially. The research methodology used is, the researcher uses a design using descriptive methods and quantitative methods. The data used are secondary data and primary data. The population in this study were 150 economic students at STIE Graha Karya Muara Bulian Jambi. The sample in this study was 60 respondents to the students of the Faculty of Economics STIE Graha Karya Muara Bulian Jambi. The results of multiple linear regression obtained $Y=-0.386+0.667 X 1+0.221 X 2+0.458 X 3-0.163 X 4+e$, Based on the coefficient of determination it can be seen that brand image, Price, Promotion and Electronic Word of Mouth have an effect on purchase decisions amounted to $75.6 \%$, while the remaining $24.4 \%$ is influenced by other variables. Based on the results of the $f$ test regression, it can be seen that the value of $f$ count is $42.71>f$ table 2.54 , which means brand image, price, promotion and electronic word of mouth have a positive and significant effect on purchasing decisions.
\end{abstract}

Keywords: Brand Image, Price, Promotion, Electronic Word of Mouth and Purchase Decision

\section{Pendahuluan}

Dalam menghadapi persaingan pemasaran yang semakin tajam, seorang produsen tidak boleh terpaku pada bentuk produk yang menawarkan manfaat dasarnya saja (Hartanty \& Ratnawati, 2013). Persaingan sekarang bukanlah apa yang diproduksi perusahaan dalam pabrik tetapi antara apa yang mereka tambahkan pada hasil pabrik tersebut dalam bentuk pengemasan, iklan, konsultan bagi pelanggan, pendanaan, pengiriman, pergudangan dan hal-hal lainnya yang dipandang perlu. Dengan demikian keberhasilan menjual suatu produk sangat ditentukan oleh keterampilan mengelola produk inti (core product), produk tambahan (Augmented product) dan produk yang disempurnakan yang berbeda dari pesaingnya.

Salah satu industri pasar yang saat ini mengalami persaingan yang ketat dalam kegiatan memasarkan produknya guna memperebutkan konsumen adalah industri pasar kosmetik. Munculnya ancaman bisnis baru di bidang kosmetik menyebabkan perusahaan harus mengembangkan dan merebut pangsa pasar. Kosmetik saat ini telah menjdi kebutuhan manusia yang tidak bisa di angap sebelah mata lagi. Jika disadari bahwa wanita maupun pria sejak lahir sampai dewasa semua membutuhkan kosmetik. Bermacam-macam produk kosmetik mulai bemunculan dimana perusahaan-perusahaan kosmetik saling bersaing untuk mendapatkan persepsi yang baik dari konsumen terhadap merek dari produk mereka. Konsumen pada saat ini sangat selektif dalam memilih sebuah produk, sampai pada akhirnya mereka melakukan keputusan untuk membeli produk tersebut. Sebagaimana kita ketahui bahwa produk yang ditawarkan sangat beraneka ragam sesuai dengan trand saat ini. Konsumen akan memilih sebuah produk selain yang memiliki kualitas yang baik juga mereka akan memilih sebuah merek yang cukup terkenal atau mempunyai citra merek (brand image). Citra merek yang baik akan menarik minat konsumen untuk melakukan pembelian terhadap suatu produk. Citra merek yang tinggi akan menciptakan kesan positif di benak konsumen terhadap suatu produk. Di sisi lain, harga produk yang terjangkau juga dapat menciptakan pembelian konsumen karena konsumen cenderung mengutamakan produk yang harganya benar-benar terjangkau. Konsumen juga tidak me ngabaikan kualitas produk meskipun harga suatu produk tersebut murah. Kualitas produk merupakan prioritas konsumen sebelum melakukan pembelian.

Menurut (Hermawan, 2015) dikatakan harga merupakan faktor yang penting yang dapat mempengaruhi pembeli. Pada akhirnya konsumen akan memutuskan apakah harga suatu produk yang ditawarkan tetap atau tidak. Menurut (Kotier \& Zaltman, 1996) menjelaskan ada empat ukuran yang mencirikan harga, Keterjangkauan harga, Harga sesuai kemampuan atau daya saing harga, Kekesuaian harga dengan kualitas produk, Kesesuaian harga dan manfaat. Menurut (Kustin, 2010) promosi adalah usaha atau upaya untuk menjalankan atau meningkatkan perdagangan atau memajukan bidang usahanya. Menurut (Tjiptono \& Chandra, 2004) promosi adalah suatu bentuk 
Irfan Widyanto dan Albetris, Pengaruh Citra Merek, Harga, Promosi dan Electronic Word of Mouth Terhadap Keputusan Pembelian Produk Bedak Padat Wardah Pada PT Pargon Tecnology and Inovation (Studi Kasus Mahasiswa Fakultas Ekonomi STIE Graha Karya Muara Bulian)

komunikasi pemasaran, yang berusaha menyebarkan informasi, mempengaruhi atau menunjuk dan mengingatkan pasar sasaran atas perusahaan dan produknya agar bersedia menerima dan membeli, loyal pada produk yang ditawarkan perusahaan yang bersangkutan. Indikator promosi adalah : Jangkauan promosi harus sesuai dengan keadaan, Kuantitas penayangan promosi di media iklan, Kualitas penyampaian pesan dalam penayangan iklan di media promosi.

Electronic Word Of Mouth adalah pernyataan positif atau negative yang di lakukan oleh konsumen potensial, aktual, maupun mantan konsumen tentang produk atau perusahaan melalui internet (Hennig-Thurau et al., 2002). Jaringan sosial, seperti Facebook, Instagram, google, menjadi kekuatan penting dalam pemasaran bisnis ke konsumen maupun pemasaran bisnis-bisnis. (Hsu et al., 2013) membagi electronic word of mouth dalam tiga dimensi yaitu: Pertama, Intensity dalam eWOM adalah banyaknya pendapat yang ditulis oleh konsumen dalam sebuah situs jejaring sosial. Kedua, Valence of opinion didefinisikan sebagai komentar yang disebarkan oleh konsumen yang bersifat positif dan negatif. Ketiga, WOM Content merupakan komentar yang dilontarkan antar pengguna mengenai mengenai konten dari produk, seperti kualitas, penggunaan, dan lain-lainnya.

PT. Paragon Tecnology and Inovation merupakan salah satu perusahaan manufaktur kosmetik nasional terbesar yang ada di Indonesia dan telah diperhitungkan dalam taraf internasional juga. Selain itu PT. Paragon telah mendapatkan sertifikat GMP (Good Manucfaturing Pratice). Keputusan konsumen dalam menentukan atau memilih merek kosmetik tertentu bukanlah hal yang begitu saja terjadi. Banyak pertimbangan yang dilakukan konsumen sebelum memutuskan untuk membeli suatu produk misalnya, harga, kualitas prouk dan iklan. Data penjualan kosmetik di Indonesia selama dua tahun terakhir tahun 2019-2020 mengalami kenaikan dan penurunan. Terdapat 3 produk kosmetik yang bersaing ketat untuk merebut pangsa pasar, yaitu Pond's, Wardah dan citra. Banyaknya pilihan produk komsetik yang membuat para konsumen harus hati-hati dalam pemakaiannya, tekhususnya untuk para wanita. Produk kosmetik yang berlabel halal menjadi salah satu kriteria dalam pemilihan produk dari kosmetik. Produk kosmetik yang berlabel halal di Indonesia adalah yang telah memiliki sertifikat halal yang dikeluarkan oleh Lembaga Pengkajian Pangan, Obat-obatan dan Kosmetika Majelis Ulama Indonesia (LPPOM MUI). Wardah Cosmetic's adalah pesaing kosmetik selain berlabel halal di Indonesia produk wardah ini memiliki keunggulan atau kelebihan lain yaitu variasi produknya banyak, berkualias tinggi serta pas dipakai sesuai dengan type kulit yang membelinya. Wardah Cosmetic's adalah produk kecantikan wanita Indonesia yang aman dan berkaulitas tinggi dengan memproduksi kosmetika untuk bermacam jenis kulit. Wardah cosmetic's aman bagi kulit para wanita karena kosmetik ini terbuat dari bahan-bahan yang alami dan terpercaya.

Tabel 1

Top Brand Indeks Kategori Bedak Muka Tabur

\begin{tabular}{|l|r|r|}
\hline \multicolumn{1}{|c|}{ BRAND } & TBI 2021 & Kategori \\
\hline Wardah & & TOP \\
\hline Pixy & $26.7 \%$ & TOP \\
\hline Make Over & $10.8 \%$ & $7.8 \%$ \\
\hline Maybelline & $7.4 \%$ & \\
\hline Caring & $6.7 \%$ & \\
\hline
\end{tabular}

Sumber : https://www.topbrand-award.com/en/top-brand-index-int/

Data terlihat bahwa dari 5 merek terkenal bedak padatnya produk dari Wardah menjadi pesaing tertinggi dari pada Produk Pixy, Carring, Maybeline dan Make Over. Selain itu terlihat dari data bahwa dari penjualan produk wardah dikota Jambi cukup tinggi yaitu tiap bulannya hampir 3000 pes terjual produknya. Sejauh ini pada umumnya mahasiswa ekonomi di STIE Graha Karya Muara Bulian Jambi sudah mengetahui dan menggunakan produk kecantikan dari wardah. Diketahui Jumlah mahasiswa STIE Graha Karya Muara Bulian Jambi Tahun 2021 sebanyak 315 orang. Tujuan penelitian ini adalah untuk mengetahui Bagaimana electronic word of mouth terhadap keputusan pembelian produk bedak padat wardah pada pt pargon tecnology and inovation (studi kasus mahasiswa fakultas ekonomi stie graha karya muara bulian).

\section{Landasan Teori}

\section{Electronic Word Of Mouth}

Electronic Word Of Mouth adalah pernyataan positif atau negative yang di lakukan oleh konsumen potensial, aktual, maupun mantan konsumen tentang produk atau perusahaan melalui internet (Hennig-Thurau et al., 2004). Jaringan sosial, seperti Facebook, Instagram, google, menjadi kekuatan penting dalam pemasaran bisnis ke konsumen maupun pemasaran bisnis-bisnis. (López \& Sicilia, 2014) membagi electronic word of mouth dalam tiga dimensi yaitu: Pertama, Intensity dalam eWOM adalah banyaknya pendapat yang ditulis oleh konsumen dalam sebuah 
Irfan Widyanto dan Albetris, Pengaruh Citra Merek, Harga, Promosi dan Electronic Word of Mouth Terhadap Keputusan Pembelian Produk Bedak Padat Wardah Pada PT Pargon Tecnology and Inovation (Studi Kasus Mahasiswa Fakultas Ekonomi STIE Graha Karya Muara Bulian)

situs jejaring sosial. Kedua, Valence of opinion didefinisikan sebagai komentar yang disebarkan oleh konsumen yang bersifat positif dan negatif. Ketiga, WOM Content merupakan komentar yang dilontarkan antar pengguna mengenai mengenai konten dari produk, seperti kualitas, penggunaan, dan lain-lainnya.

\section{Perilaku Konsumen}

Menurut (Arifuddin, 2012), perilaku konsumen adalah studi proses yang terlibat ketika individu atau kelompok memilih, membeli. Menggunakan, atau mengatur produk, jasa, idea atau pengalaman untuk memuasakan kebutuhan dan keinginan konsumen. Menurut (Kartikasari, 2013), mendefinisikan perilaku konsumen yaitu: "Perilaku konsumen adalah tindakan yang langsung terlibat dalam mendapatkan, mengkonsumsi, dan menghabiskan, produk atau jasa, termasuk proses keputusan yang mendahului dan meyusuli tindakan ini." Definisi menurut The American Marketing Association yang dikutip (Evelina et al., 2012) mendefinisikan perilaku konsumen sebagai: "Perilaku konsumen merupakan interaksi dinamis antara afeksi dan kognisi, perilaku, dan lingkungannya dimana manusia melakukan kegiatan pertukaran".

Faktor- faktor Yang Mempengaruhi Perilaku Konsumen Menurut (Hanafi, 2015) yaitu: Faktor budaya; faktor social, faktor pribadi; faktor psikologi.

\section{Keputusan Pembelian}

Menurut (Kartikasari, 2013) keputusan pembelian adalah suatu tahap dimana konsumen telah memiliki pilihan dan siap untuk melakukan pembelian atau pertukaran antara uang dan janji untuk membayar dengan hak kepemilikan atau penggunaan suatu barang atau jasa. Sementara itu menurut (J. P. Peter \& Olson, 2009) keputusan pembelian adalah proses mengkombinasikan pengetahuan untuk mengevaluasi dua atau lebih perilaku alternatif dan memilih salah satu diantaranya. Sementara itu (P. J. Peter \& Olson, 2012) menyebutkan bahwa keputusan pembelian merupakan suatu proses pengambilan keputusan akan pembelian yang mencakup penentuan apa yang akan dibeli atau tidak melakukan pembelian dan keputusan itu diperoleh dari kegiatan-kegiatan sebelumnya , maka dapat diambil kesimpulan bahwa keputusan pembelian adalah suatu proses pengambilan keputusan akan pembelian yang akan menentukan dibeli atau tidaknya pembelian tersebut yang diawali dengan kesadaran atas pemenuhan atau keinginan.

Menurut (Kotler et al., 1996) dimensi dalam keputusan pembelian ada lima sub keputusan :

1. Produk, yaitu pelanggan menginginkan produk/jasa yang sesuai dengan kebutuhan dan harapan pada suatu tingkat harga tertentu yang menunjukkan nilai produk tersebut.

2. Merek, yaitu nama atau simbol yang bersifat membedakan (baik berupa logo, cap/kemasan) untuk mengidentifikasi barang/jasa dari seorang penjual tertentu.

3. Penyalur, yaitu pihak terkait sebelum proses yang menjadi objek obeservasi. Penyalur harus menyiapkan masukan input sesuai permintaan diri sendiri.

4. Waktu Pembelian, yaitu proses rangkaian saait ketika proses, perbuatan atau keadaan berlangsung.

5. Metode Pembayaran, yaitu setelah memilih salah satu alternatif yang ada. Metode pembayaran dilakukan dengan cara tunai/kartu kredit

\section{Indikator Keputusan Pembelian}

Indikator menurut (Kotier \& Zaltman, 1996) Keputusan Pembelian ada beberapa sebagai berikut : Kemantapan pada sebuah produk; Kebiasaan dalam membeli produk; Memberikan rekomendasi kepada orang lain; dan Melakukan pembelian ulang.

\section{Hubungan Antar Variabel \\ Hubungan Citra Merek Dengan Keputusan Pembelian}

Menciptakan kesan menjadi salah satu karakteristik dasar dalam orientasi pemasaran modern yaitu lewat pemberian perhatian lebih serta penciptaan merek yang kuat. Implikasi dari hal tersebut menjadikan merek suatu produk menciptakan image dari produk itu sendiri di benak pikiran konsumen dan menjadikan motivasi dasar bagi konsumen dalam memilih suatu produk. Brand imageyang dikelola dengan baik akan menghasilkan konsekuensi yang positif, salah satunya adalah meningkatkan pemahaman terhadap aspek-aspek perilaku konsumen dalam mengambil keputusan pembelian. Suatu produk dengan citra merek yang baik dan diyakini konsumen dapat memenuhi kebutuhan dan keinginannya, maka dengan sendirinya akan menumbuhkan keputusan pembelian konsumen akan produk yang ditawarkan bahkan produk tersebut akan bertahan lama di pasaran. Sebaliknya apabila produk dengan citra merek yang kurang baik dalam pandangan konsumen, maka keputusan pembelian konsumen terhadap produk juga akan lebih rendah(Hermawan, 2015). 
Irfan Widyanto dan Albetris, Pengaruh Citra Merek, Harga, Promosi dan Electronic Word of Mouth Terhadap Keputusan Pembelian Produk Bedak Padat Wardah Pada PT Pargon Tecnology and Inovation (Studi Kasus Mahasiswa Fakultas Ekonomi STIE Graha Karya Muara Bulian)

\section{Hubungan Harga Terhadap Keputusan Pembelian}

Menurut (Tjiptono \& Chandra, 2004) Hubungan harga merupakan satuan moneter atau ukuran lainnya (termasuk barang dan jasa lainya) yang ditukarakan agar memperoleh hak kepemilikan atau penggunaan suatu barang atau jasa.

\section{Hubungan Promosi Terhadap Keputusan Pembelian}

Promosi merupakan salah satu variabel marketing mix yang memiliki peran penting bagi perusahaan dalam upaya memasarkan produk atau jasanya.

\section{Hubungan Electronic Word Of Mouth Terhadap Keputusan Pembelian}

Electronic word of mouth banyak digunakan oleh konsumen yang sedang mencari review atau pendapat mengenai suatu produk melalui situs atau forum-forum berbasis online. Karena kemudahan dan jangkauannya yang luas dari berbagai pihak yang merespon sebuah pendapat.Pendapat bisa positif dan bisa negatif, karena selera konsumen yang berbeda.Pendapat ini bisa digunakan oleh calon konsumen untuk memutuskan membeli atau tidak suatu produk tertentu. Ketika konsumen mendapatkan tanggapan positif maka konsumen cenderung akan membeli produk tersebut. Dengan demikian, hubungan antara eWom dan keputusan pembelian bisa negatif ataupun positif.

\section{Hipotesis}

Diduga Terdapat pengaruh citra merek, harga, promosi dan electronic word of mouth terhadap keputusan pembelian produk bedak padat wardah pada pt pargon tecnology and inovation (studi kasus mahasiswa fakultas ekonomi stie graha karya muara bulian) secara parsial.

\section{Metode}

Sumber data primer adalah menyebarkan kuisoner pada Mahasiswa fakultas ekonomi STIE Graha Karya Muara Bulian. Untuk memperoleh data dan informasi yang diperlukan maka pengumpulan data dan informasi tersebut dilakukan dengan cara observasi pada mahasiswa fakultas ekonomi STIE Graha Karya Muara Bulian, kegiatan ini dilakukan dengan tujuan untuk mengamati dan mendapatkan data dan informasi terhadap kegiatan-kegiatan yang akan diteliti.

Metode kuisioner yaitu metode pengumpulan data dengan cara mengisi daftar pertanyaan dengan membagibagikan kuisioner kepada Mahasiswa fakultas ekonomi STIE Graha Karya Muara Bulian agar dapat mengisi daftar pertanyaan diharapkan dari metode ini diperoleh data yang akurat dan meyakinkan atas masalah yang diteliti. Dalam metode kuisioner ini dilakukan dengan cara membagikan angket atau kuisoner kepada Mahasiswa fakultas ekonomi STIE Graha Karya Muara Bulian.

Dalam penelitian ini yang menjadi populasi penelitian adalah seluruh Mahasiswa Perempuan Fakultas Ekonomi STIE Graha Karya Muara Bulian Yang Pernah Membeli Produk Bedak Padat Wardah pada PT Pargon Tecnology and Inovation sebanyak 150 Orang. Dalam penentuan sampel penulis menggunakan random sampling yaitu penarikan sampel secara acak terhadap responden. Adapun pengambilan sampel dalam penelitian ini dengan cara rumus Slovin sebagai berikut :

$\mathrm{n}=\mathrm{N} /(1+\llbracket \mathrm{Ne} \rrbracket \wedge 2)$

$\mathrm{n}=150 /\left(1+150 * 0,1^{\wedge} 2\right) \mathrm{n}=60$

Dimana : $\mathrm{n}=$ ukuran sampel; $\mathrm{N}=$ ukuran populasi; $\mathrm{e}=$ persentase kelonggaran ketidak telitian karena kesalahan pengambilan sampel yang masih dapat di tolerir atau dinginkan, misalnya 10\%; $1=$ konstanta

Jumlah sampel yang akan diteliti yaitu 60 responden. Objek Mahasiswa Perempuan Fakultas Ekonomi STIE Graha Karya Muara Bulian Yang Pernah Membeli Produk Bedak Padat Wardah pada PT Pargon Tecnology and Inovation. Teknik penarikan sampel dilakukan secara non probability simple random sampling. Dimana sampel diambil dengan bertemu secara langsung Mahasiswa Perempuan Fakultas Ekonomi STIE Graha Karya Muara Bulian Yang Pernah Membeli Produk Bedak Padat Wardah pada PT Pargon Tecnology and Inovation, skala yang adalah skalalikert dimana: Nilai 5 = sangat setuju; Nilai $4=$ setuju; Nilai $3=$ kurang setuju; Nilai $2=$ tidak setuju; Nilai $1=$ sangat tidak setuju

\section{Analisis Regresi linier Berganda}

\section{$\mathbf{Y}=\mathbf{a}+\mathbf{b} \mathbf{X}_{1}+\mathbf{b} \mathbf{X}_{2}+\mathbf{b} \mathbf{X}_{3}+\mathbf{b} \mathbf{X}_{4}+\mathbf{e}$}

Dimana : Y : Keputusan pembelian; a : konstanta; $\mathrm{X}_{1}$ : Citra Merk; $\mathrm{X}_{2}$ : Harga; $\mathrm{X}_{3}$ : Promosi; $\mathrm{X}_{4}$ : lectronic Word of Mouth; B : Koefisien Regresi; e : Nilai error 
Irfan Widyanto dan Albetris, Pengaruh Citra Merek, Harga, Promosi dan Electronic Word of Mouth Terhadap Keputusan Pembelian Produk Bedak Padat Wardah Pada PT Pargon Tecnology and Inovation (Studi Kasus Mahasiswa Fakultas Ekonomi STIE Graha Karya Muara Bulian)

\section{Hasil}

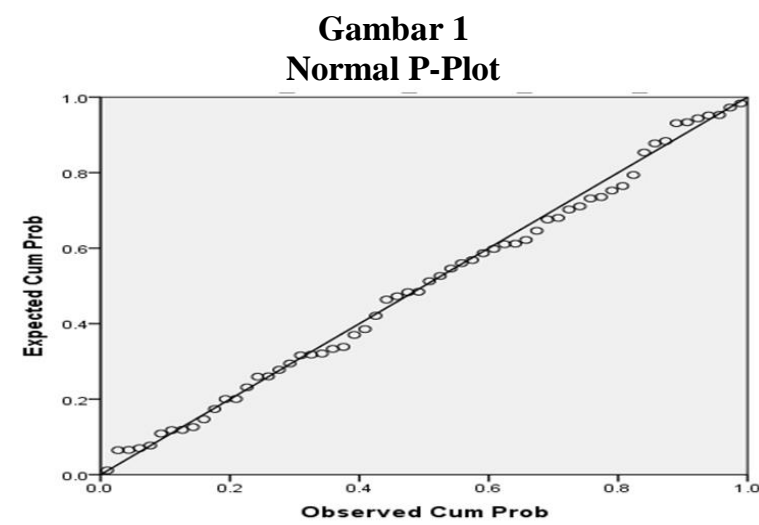

Berdasarkan hasil uji normalitas, dapat dilihat dari Gambar 1 diatas (Normal P-Plot of Regression Standardized Residual) terlihat bahwa titik-titik yang ada mendekati garis diagonal. Jika distribusi data residual normal, maka garis yang menggambarkan data sesungguhnya akan mengikuti garis diagonalnya. Dengan demikian dapat disimpulkan bahwa model fit atau baik dan dapat dinyatakan pula bahwa distribusi data residual normal.

Tabel 2

Multikolinearitas

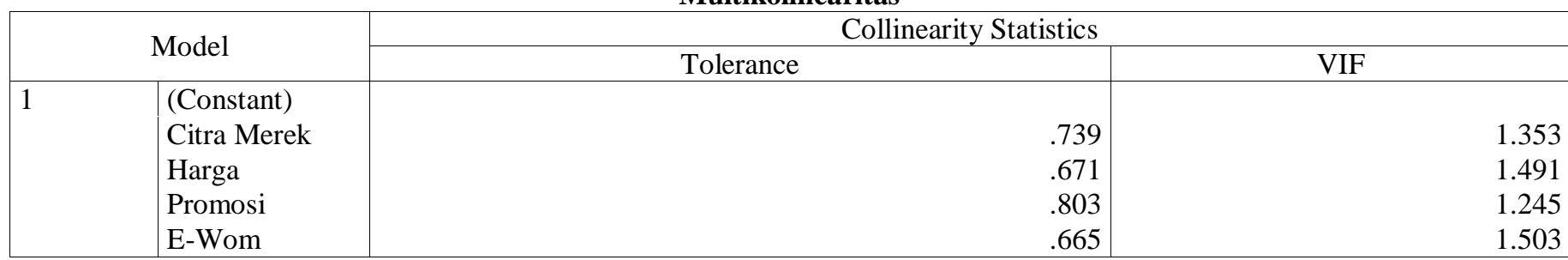

Sumber: data olahan

Pada tabel diatas menunjukkan nilai VIF seluruh variabel independen berada dibawah 10 dan nilai tolerance tidak $<0,1$ hal ini berarti bahwa diantara variabel independen didalam penelitian ini tidak terjadi hubungan atau tidak memiliki hubungan satu sama lainnya. Sehingga dapat disimpulkan bahwa model regresi tidak terjadi multikolinearitas.

Tabel 3

Model Summary ${ }^{b}$

\begin{tabular}{|c|l|r|r|r|r|}
\hline Model & R & \multicolumn{1}{c|}{ R Square } & Adjusted R Square & Std. Error of the Estimate & Durbin-Watson \\
\hline 1 & $.870^{\mathrm{a}}$ & .756 & .739 & .02631 & .539 \\
\hline
\end{tabular}

Sumber: data olahan

Pada Tabel 3 dapat dilihat bahwa DW adalah sebesar 0,539 ini berarti dengan melihat kriteria pengambilan keputusan, maka dapat disimpulkan dalam model regresi tidak terjadi autokorelasi karena nilai 0,539 berada diantara 2 dan +2 atau $(-2<0,539<2)$.

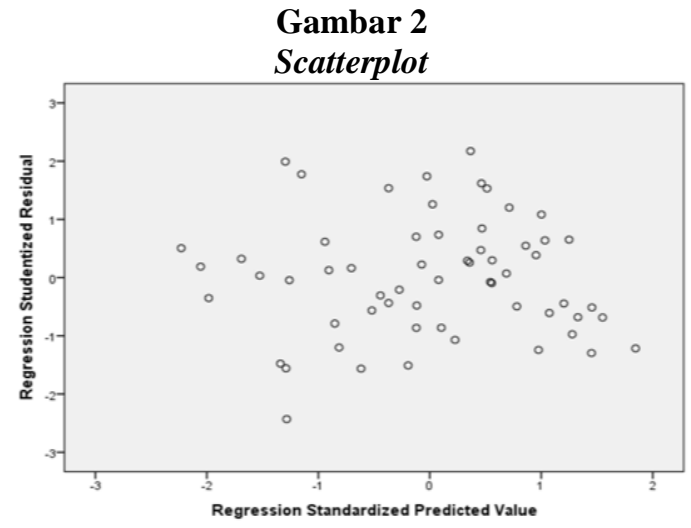


Irfan Widyanto dan Albetris, Pengaruh Citra Merek, Harga, Promosi dan Electronic Word of Mouth Terhadap Keputusan Pembelian Produk Bedak Padat Wardah Pada PT Pargon Tecnology and Inovation (Studi Kasus Mahasiswa Fakultas Ekonomi STIE Graha Karya Muara Bulian)

Dalam suatu model regresi yang baik, biasanya tidak mengalami heteroskedasitas. Melalui grafik scatterplot dapat dilihat suatu model regresi mengalami heteroskedasitas atau tidak. Jika terdapat pola tertentu dalam grafik maka mengindikasikan telah terjadi heteroskasitas. Dari gambar terlihat bahwa titik-titik menyebar secara acak serta tersebar baik diatas maupun dibawah angka 0 pada sumbu Y. Maka dapat disimpulkan bahwa tidak terjadi heteroskedasitas pada model regresi dalam penelitian ini.

Tabel 4

Coefficients $^{\mathbf{a}}$

\begin{tabular}{|c|c|c|c|c|c|}
\hline \multirow[b]{2}{*}{ Model } & \multicolumn{2}{|c|}{ Unstandardized Coefficients } & \multirow{2}{*}{$\begin{array}{c}\text { Standardized Coefficients } \\
\text { Beta }\end{array}$} & \multirow[b]{2}{*}{$\mathrm{t}$} & \multirow[b]{2}{*}{ Sig. } \\
\hline & $\mathrm{B}$ & Std. Error & & & \\
\hline $1 \quad$ (Constant) & -.386 & .916 & & -.514 & .609 \\
\hline Citra Merek & .667 & .115 & .449 & 5.802 & .000 \\
\hline Harga & .221 & .055 & .325 & 3.994 & .000 \\
\hline Promosi & .458 & .223 & .152 & 2.052 & .045 \\
\hline E-Wom & -.163 & .048 & -.276 & -3.380 & .001 \\
\hline
\end{tabular}

Sumber: data olahan

Berdasarkan tabel diatas, maka diperoleh persamaan regresi sebagai berikut:

$\mathrm{Y}=-0,386+0,667 \mathrm{X}_{1}+0,221 \mathrm{X}_{\mathrm{p}}+0,458 \mathrm{X}_{\mathrm{s}}-0,163 \mathrm{X}_{4}+\mathrm{e}$

Dari persamaan diatas dapat dijelaskan beberapa hal sebagai berikut:

1. Nilai konstanta sebesar - 0,386 menunjukkan bahwa variabel Citra Merek, harga, Promosi, dan E-Wom tidak mengalami perubahan, maka Keputusan Pembelian memiliki nilai tetap sebesar - 0,386.

2. Variabel Citra Merek mempunyai koefisien regresi dengan arah positif sebesar 0,667. Hal ini menunjukkan jika Citra meningkat sebesar 1\% maka akan menaikkan Keputusan Pembelian sebesar 66,7\%.

3. Variabel Harga mempunyai koefisien regresi dengan arah positif sebesar 0,221. Hal ini menunjukkan jika harga meningkat sebesar 1\% maka akan menaikkan Keputusan Pembelian sebesar 22,1\%.

4. Variabel Promosi mempunyai koefisien regresi dengan arah positif sebesar 0,458. Hal ini menunjukkan jika promosi meningkat 1\% maka akan menaikkan Keputusan Pembelian sebesar 45,8\%.

5. Variabel E-Wom mempunyai koefisien regresi dengan arah negatif sebesar -0,163. Hal ini menunjukkan jika EWom meningkat 1\% maka akan menurunkan Keputusan Pembelian sebesar -16,3\%.

Tabel 5

ANOVA $^{\mathrm{a}}$

\begin{tabular}{|l|l|r|r|r|r|r|}
\hline \multicolumn{2}{|c|}{ Model } & Sum of Squares & Df & Mean Square & F & Sig. \\
\hline 1 & Regression & .118 & 4 & .030 & 42.711 & $.000^{\mathrm{b}}$ \\
& Residual & .038 & 55 & .001 & \\
& Total & .156 & 59 & & \\
\hline
\end{tabular}

Sumber: data olahan

Pengujian ini dilakukan dengan cara membandingkan nilai $\mathrm{F}$ hitung dan $\mathrm{F}$ tabel. Untuk mencari $\mathrm{F}$ tabel maka digunakan rumus (n-k-1 atau 60-4-1 = 55) dengan tingkat signifikan 0,05\%. Hasil yang diperoleh yaitu 2,54. Berdasarkan tabel 4.4 diperoleh nilai $\mathrm{F}$ hitung sebesar 42,71. Hal ini menunjukkan bahwa nilai $\mathrm{F}$ hitung lebih besar dari $\mathrm{F}$ tabel $(42,71>2,54)$ dan nilai signifikan lebih kecil dari nilai alfa $(0,000<0,05)$. Dengan demikian Ho ditolak dan Ha diterima. Artinya Citra Merek, Harga, Promosi, E-Wom berpengaruh signifikan terhadap terhadap keputusan pembelian produk bedak padat wardah pada pt pargon tecnology and inovation secara simultan.

Uji t digunakan untuk mengetahui apakah variabel independen secara parsial berpengaruh terhadap variabel dependen. Pengujian ini dilakukan dengan cara membandingkan nilai $t$ hitung dan $t$ tabel. Untuk mencari t tabel maka digunakan rumus (n-k-1 atau 60-4-1 = 55) dengan tingkat signifikan 0,05\%. Hasil yang diperoleh yaitu sebesar 2,00404. Hasil uji tersebut dapat dilihat pada tabel 4. Berdasarkan tabel 4 diatas dapat diketahui nilai t hitung dari setiap variabel adalah sebagai berikut:

a. Pengaruh Citra Merek Terhadap Keputusan Pembelian

Berdasarkan tabel diatas dapat diperoleh nilai signifikan lebih kecil daripada alfa $(0,000<0,05)$ dan nilai t hitung lebih besar dari t tabel $(5,802>2,00404)$. Dengan demikian hipotesis diterima, artinya Citra Merek berpengaruh signifikan terhadap Keputusan pembelian produk bedak padat wardah pada pt pargon tecnology and inovation .

b. Pengaruh Harga Terhadap Keputusan Pembelian 
Irfan Widyanto dan Albetris, Pengaruh Citra Merek, Harga, Promosi dan Electronic Word of Mouth Terhadap Keputusan Pembelian Produk Bedak Padat Wardah Pada PT Pargon Tecnology and Inovation (Studi Kasus Mahasiswa Fakultas Ekonomi STIE Graha Karya Muara Bulian)

Berdasarkan tabel diatas diperoleh nilai signifikan lebih kecil daripada alfa $(0,000<0,05)$ dan nilai t hitung lebih besar dari t tabel $(3,994>2,00404)$. Dengan demikian hipotesis diterima, artinya Harga berpengaruh signifikan terhadap Keputusan pembelian produk bedak padat wardah pada pt pargon tecnology and inovation .

c. Pengaruh Promosi Terhadap Keputusan Pembelian

Berdasarkan tabel diatas diperoleh nilai signifikan lebih kecil daripada alfa $(0,045<0,05)$ dan nilai $\mathrm{t}$ hitung lebih besar dari t tabel $(2,052>2,00404)$. Dengan demikian hipotesis diterima, artinya Promosi berpengaruh signifikan terhadap Keputusan pembelian produk bedak padat wardah pada pt pargon tecnology and inovation .

d. Pengaruh E-Wom Terhadap Keputusan Pembelian

Berdasarkan tabel diatas diperoleh nilai signifikan lebih kecil daripada alfa $(0,001<0,05)$ dan nilai $t$ hitung lebih kecil dari t tabel $(-3,380<2,00404)$. Dengan demikian hipotesis ditolak, artinya E-Wom tidak berpengaruh signifikan terhadap Keputusan pembelian produk bedak padat wardah pada pt pargon tecnology and inovation .

Berdasarkan pada Tabel 3 angka $\mathrm{R}^{2}$ (R Square) sebesar 0,756. Hal ini menunjukkan bahwa persentase Citra

Merek, Harga, Promosi, dan E-Wom terhadap Keputusan Pembelian sebesar 75,6\%. Dengan kata lain variabel Keputusan Pembelian dapat dipengaruhi oleh variabel Citra Merek, Harga, Promosi, dan E-Wom sebesar 75,6\% sedangkan sisanya sebesar 24,4\% dipengaruhi oleh variabel lain yang tidak diteliti. Hasil penelitian ini sejalan dengan penelitian yang dilakukan oleh (haryanto \& Yunita, 2012) yang menunjukkan bahwa E-Wom berpengaruh terhadap Keputusan Pembelian. Nilai Koefisien determinasi (R Square) sebesar 0,756. Hal ini menunjukkan bahwa persentase Citra Merek, Harga, Promosi, dan E-Wom terhadap Keputusan Pembelian sebesar 75,6\%. Dengan kata lain variabel Keputusan Pembelian dapat dipengaruhi oleh variabel Citra Merek, Harga, Promosi, dan E-Wom sebesar 75,6\% sedangkan sisanya sebesar 24,4\% dipengaruhi oleh variabel lain yang tidak diteliti.

\section{Simpulan}

Berdasarkan hasil penelitian dan pembahasan yang telah diuraikan diatas, maka kesimpulan dari penelitian ini adalah:

1. Citra Merek, Harga, Promosi, dan E-Wom secara Simultan berpengaruh terhadap Keputusan pembelian produk bedak padat wardah pada pt pargon tecnology and inovation .

2. Citra Merek, Harga, Promosi Secara Parsial berpengaruh terhadap Keputusan Pembelian tetapi E-Wom secara Parsial tidak berpengaruh terhadap Keputusan pembelian produk bedak padat wardah pada pt pargon tecnology and inovation.

\section{Daftar Pustaka}

Arifuddin, A. (2012). Faktor-faktor yang Mempengaruhi Perilaku Konsumen dalam Keputusan Membeli Komputer di Lingkungan Mahasiswa Fakultas Ekonomi dan Bisnis Universitas Hasanuddin. 6(2), 1-94.

Elizar, Suripin, \& Wibowo, M. A. (2017). Model of Construction Waste Management Using AMOS-SEM for Indonesian Infrastructure Projects. MATEC Web of Conferences, 138. https://doi.org/10.1051/matecconf/201713805005

Evelina, N., Dw, H., \& Listyorini, S. (2012). Pendahuluan Perkembangan kegiatan-kegiatan manusia dewasa ini bergerak dengan pesat. Salah satu mempermudah kegiatan manusia, diantaranya adalah teknologi informasi . Teknologi informasi melawan kompetitor seluler baik untuk produk CDMA maupun GSM yang. PENGARUH CITRA MEREK, KUALITAS PRODUK, HARGA, DAN PROMOSI TERHADAP KEPUTUSAN PEMBELIAN KARTU PERDANA TELKOMFLEXI (Studi Kasus Pada Konsumen TelkomFlexi Di Kecamatan Kota Kudus Kabupaten Kudus), $c$.

Hanafi, M. (2015). Konsep Dasar dan Perkembangan Teori Manajemen. Managemen, 1(1), 66. http://repository.ut.ac.id/4533/1/EKMA4116-M1.pdf

Harraveld, B., Danaher, M., Lawson, C., Knight, B. A., \& Busch, G. (2016). Constructing Methodology for Qualitative Research: Second Edtition.

Hartanty, I. T., \& Ratnawati, A. (2013). Peningkatan kinerja pemasaran melalui optimalisasi keunggulan bersaing. Jurnal Ekonomi Dan Bisnis, 14(2), 72-89.

haryanto, jony, \& Yunita, A. (2012). Pengaruh Word of Mouth, Iklan Dan Atribut Produk Terhadap Keputusan Pembelian Dan Loyalitas Konsumen. Journal of Technology Management, 11(1).

Hennig-Thurau, T., Gwinner, K. P., \& Gremler, D. D. (2002). Understanding Relationship Marketing Outcomes: An Integration of Relational Benefits and Relationship Quality. Journal of Service Research, 4(3), 230-247. https://doi.org/10.1177/1094670502004003006

Hennig-Thurau, T., Gwinner, K. P., Walsh, G., \& Gremler, D. D. (2004). Electronic word-of-mouth via consumeropinion platforms: What motivates consumers to articulate themselves on the Internet? Journal of Interactive Marketing, 18(1), 38-52. https://doi.org/10.1002/dir.10073 
Irfan Widyanto dan Albetris, Pengaruh Citra Merek, Harga, Promosi dan Electronic Word of Mouth Terhadap Keputusan Pembelian Produk Bedak Padat Wardah Pada PT Pargon Tecnology and Inovation (Studi Kasus Mahasiswa Fakultas Ekonomi STIE Graha Karya Muara Bulian)

Hermawan, H. (2015). Analisis Pengaruh Bauran Pemasaran Terhadap Keputusan, Kepuasan Dan Loyalitas Konsumen Dalam Pembelian Roti Ceria Di Jember. Jurnal Manajemen Dan Bisnis Indonesia, 3(2), 143-158.

Hsu, L. C., Wang, K. Y., \& Chih, W. H. (2013). Effects of web site characteristics on customer loyalty in B2B ecommerce: evidence from Taiwan. The Service Industries Journal. https://www.tandfonline.com/doi/abs/10.1080/02642069.2011.624595

Johann Mouton, H. M. (2010). Basic concepts in methodology of the social sciences. In Studies in Fuzziness and Soft Computing (Vol. 246). https://doi.org/10.1007/978-3-642-10695-8_1

Kartikasari, D. (2013). Pengaruh Perilaku Konsumen Terhadap Keputusan Pembelian. Jurnal Administrasi Bisnis S1 Universitas Brawijaya, 3(2), 74110.

Keller, K. L. (2009). Building strong brands in a modern marketing communications environment. Journal of Marketing Communications, 15(2-3), 139-155. https://doi.org/10.1080/13527260902757530

Kotier, P., \& Zaltman, G. (1996). Social marketing: An approach to planned social change. Social Marketing Quarterly, 3(3-4), 7-20. https://doi.org/10.1080/15245004.1996.9960973

Kotler, P., Armstrong, G., Saunders, J., \& Wong, V. (1996). principles of marketing.

Kotler, P., \& Keller, K. L. (2006). Marketing Management Twelfth Edition. In Organization.

Kustin, R. (2010). The earth is flat, almost: Measuring marketing standardization and profit performance of Japanese and U.S. firms. Journal of Global Marketing, 23(2), 100-108. https://doi.org/10.1080/08911761003673371

Livingston, M. (2009). Multilevel Analysis for Applied Research-It's Just Regression! In Drug and Alcohol Review (Vol. 28, Issue 1). https://doi.org/10.1111/j.1465-3362.2008.00013_5.x

López, M., \& Sicilia, M. (2014). Determinants of E-WOM influence: The role of consumers' internet experience. Journal of Theoretical and Applied Electronic Commerce Research, 9(1), $28-43$. https://doi.org/10.4067/S0718-18762014000100004

Peter, J. P., \& Olson, J. C. (2009). Consumer Behavior \& Marketing Strategy. In Dana.

Peter, P. J., \& Olson, J. C. (2012). Consumer Behavior Marketing.

philip kotler. (1981). marketing insights from a to z. Journal of Chemical Information and Modeling, 53(9), 16891699.

Riyono, \& Gigih Erlik Budiharja. (2016). Pengaruh Kualitas Produk, Harga, Promosi Dan Brand Image Terhadap Keputusan Pembelian Produk Aqua. Jurnal Stie Semarang, 8(2), 92-121.

Rokhayati, I. (2014). Perkembangan Teori Manajemen dari Scientific Manajemen hingga era moderen. Jurnal Ekonomi Dan Bisnis, 15(September), 8.

shelby d. hunt. (2010). marketing theory (1st ed.). Routledge. http://library1.nida.ac.th/termpaper6/sd/2554/19755.pdf

Singh, P., \& Talwar, H. K. (1991). Estimation of Population Regression Coefficient in Successive Sampling. Biometrical Journal, 33(5), 599-605. https://doi.org/10.1002/bimj.4710330513

Storbacka, K., \& Nenonen, S. (2011). Corporate Brand Building. European Journal of Marketing, 45(1/2), 241-258. http://www.emeraldinsight.com/doi/10.1108/03090561111095685

Sumantri. (2019). Manajemen Keuangan Pekalongan-Indonesia (Moh. Nasrudin (ed.); 1st ed.). PENERBIT NEM PT. Nasya Expanding Management (Anggota IKAPI). www.penerbitnem.com

Tjiptono, F., \& Chandra, G. (2004). Tjiptono, Fandi. \& Chandra, Gregory. (2004). Service, Quality dan Satisfaction. Yogyakarta; Andi. Jurnal of Business and Management Sciences, 4(4), 76-81. https://doi.org/10.12691/jbms4-4-1 